\title{
Associations between the perceived presence of vending machines and food and beverage logos in schools and adolescents' diet and weight status
}

\author{
Leia M Minaker ${ }^{1}$, Kate E Storey ${ }^{2}$, Kim D Raine ${ }^{3, *}$, John C Spence ${ }^{4}$, Laura E Forbes ${ }^{2}$, \\ Ronald C Plotnikoff ${ }^{5,6}$ and Linda J McCargar ${ }^{7}$ \\ ${ }^{1}$ Department of Public Health Sciences, University of Alberta, Edmonton, AB, Canada: ${ }^{2}$ Alberta Institute of \\ Human Nutrition, University of Alberta, Edmonton, $A B$, Canada: ${ }^{3}$ Centre for Health Promotion Studies, School \\ of Public Health, University of Alberta, 1001 College Plaza, 8215-112 Street, Edmonton, AB T6G 2C8, \\ Canada: ${ }^{4}$ Sedentary Living Laboratory, Faculty of Physical Education and Recreation, University of Alberta, \\ Edmonton, AB, Canada: ${ }^{5}$ School of Education, University of Newcastle, Callaghan, NSW, Australia: ${ }^{6}$ Faculty \\ of Physical Education and Recreation and School of Public Health, University of Alberta, Edmonton, AB, \\ Canada: ${ }^{7}$ Alberta Institute of Human Nutrition, Agricultural, Food and Nutritional Science, University of Alberta, \\ Edmonton, $A B$, Canada
}

Submitted 15 May 2010: Accepted 14 February 2011: First published online 31 March 2011

\begin{abstract}
Objective: The increasing prevalence of obesity among youth has elicited calls for schools to become more active in promoting healthy weight. The present study examined associations between various aspects of school food environments (specifically the availability of snack- and beverage-vending machines and the presence of snack and beverage logos) and students' weight status, as well as potential influences of indices of diet and food behaviours.

Design: A cross-sectional, self-administered web-based survey. A series of multinomial logistic regressions with generalized estimating equations (GEE) were constructed to examine associations between school environment variables (i.e. the reported presence of beverage- and snack-vending machines and logos) and self-reported weight- and diet-related behaviours.

Setting: Secondary schools in Alberta, Canada.

Subjects: A total of 4936 students from grades 7 to 10 .

Results: The presence of beverage-vending machines in schools was associated with the weight status of students. The presence of snack-vending machines and logos was associated with students' frequency of consuming vended goods. The presence of snack-vending machines and logos was associated with the frequency of salty snack consumption.

Conclusions: The reported presence of snack- and beverage-vending machines and logos in schools is related to some indices of weight status, diet and meal behaviours but not to others. The present study supported the general hypothesis that the presence of vending machines in schools may affect students' weight through increased consumption of vended goods, but notes that the frequency of 'junk' food consumption does not seem to be related to the presence of vending machines, perhaps reflecting the ubiquity of these foods in the daily lives of students.
\end{abstract}

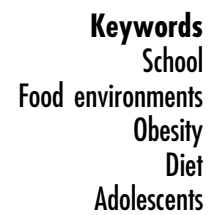

eywords

Schments

Diet

Adolescents
Schools have been identified as important settings in which to create interventions for diet and nutritional behaviours because they offer continuous and intensive contact with youth who develop lifelong habits throughout childhood and adolescence ${ }^{(1-3)}$. However, school environments may provide messages contradictory to planned interventions. For example, the availability of 'junk' food (food with little or no nutritional value beyond its energy content) in schools appears to be widespread in the $\mathrm{USA}^{(4)}$, in many European countries ${ }^{(1)}$ and in Canada ${ }^{(5-7)}$, with increased exposure for older students. For example, $95 \%$ of high schools in the USA had vending machines offering soft drinks, candy or snacks in $2005^{(8)}$. Moreover, schools in the $\mathrm{USA}^{(9,10)}$ and Canada ${ }^{(6)}$ are entering into exclusive pouring rights contracts or sponsorship agreements with multinational corporations. Pouring rights contracts involve soft-drink companies compensating schools and school districts in return for 
exclusive selling and marketing rights within schools and at school events ${ }^{(9)}$.

In 2008, the Sydney Principles for reducing the commercial promotion of foods and beverages to children were published ${ }^{(11)}$. Principle 5, to guarantee commercialfree childhood settings, recommends regulations to ensure that energy-dense, nutrient-poor foods and beverages are not marketed in child-focused settings such as schools. School policies limiting exclusive pouring rights contracts and/or the availability of vending machines in schools would be consistent with principle 5. Although reducing the consumption of such foods will have various nutritional benefits, the potential impact on childhood obesity rates is of particular interest considering the fact that the prevalence of overweight and obesity among children and adolescents continues to increase globally, with both immediate and future health consequences ${ }^{(12)}$.

A recent review concluded that, although some foodrelated school policies have been effective in improving the food environment and subsequent dietary intake among students, insufficient evidence exists regarding the relationship between school policies and obesity ${ }^{(13)}$. Findings from studies examining the relationship between these school environment factors and weight outcomes of students are also equivocal, with some studies finding associations between vending machine availability and students' weight ${ }^{(14-16)}$ and others finding no relationship ${ }^{(17)}$. Moreover, the often implicitly hypothesized pathway by which school environment factors affect students' weight, namely, by increasing 'junk food' consumption, is also contested. One recent study observed associations between the presence of pouring rights contracts, students obtaining sweetened beverages at school and increased energy consumption from sweetened beverages ${ }^{(18)}$, which is in contrast to another study indicating that sweetened beverage availability at schools may have a very limited impact on overall consumption among elementary-school children $^{(19)}$. Indeed, the picture of whether and how school food environment factors affect students' weight status is still unclear.

To date, much of the research linking school food environments and students' diet or weight outcomes has been conducted in the USA. Yet, many countries have different school food contexts; hence, generalizing these results globally can be problematic. For example, in Canada there are no government-funded school lunch or breakfast programmes ${ }^{(20)}$, nor is the nutritional content of foods available in schools regulated consistently across provincial jurisdictions. Compared with the USA, whose federal government spends approximately CAD\$212 per child per year on feeding programmes, Canadian federal and provincial governments spend $<\mathrm{CAD} \$ 6$ on school meals per student per year ${ }^{(21)}$. This difference in school food environments may result in unique relationships between the availability of vending machines, the presence of partnerships with snack or beverage companies and students' weight status. Therefore, the primary purpose of the present study was to explore and describe the association between the food environment of schools (defined as the availability of vending machines and snack and beverage logos in schools) and weight status among students of grades 7-10 in a Canadian setting. The secondary purpose of the present study was to examine selected dietary behaviours and diet quality as explanatory factors of the hypothesized relationship between school environment and students' weight status. We hypothesized that the presence of vending machines and snack and beverage logos (considered a proxy for schools' partnerships with snack or beverage companies) in schools would be associated with an increased probability of students being overweight or obese. We further hypothesized that any associations between school environmental factors and students' weight status would be attenuated by selected dietary behaviours and diet quality.

\section{Experimental methods}

\section{Subjects}

Detailed methods for the Web-Survey of Physical Activity and Nutrition (Web-SPAN) have been reported elsewhere ${ }^{(22)}$. In brief, the Web-SPAN was a self-administered web-based survey of students of grades 7-10 (aged 11-17 years) that assessed diet, physical activity and related meal behaviours. All fifty-nine school boards in the province of Alberta, Canada, were asked to participate, of which forty-four ( $75 \%$ of the total) did. An average of seven schools within each school board were randomly chosen and contacted. In total, 363 schools were contacted, of which 136 (37\%) participated. All students within the selected classrooms (18484 students) were invited to participate. In total, 5848 (32\%) students provided parental consent. However, because of schooltime constraints, only 4981 adolescents participated in the study. After excluding students who logged on to the survey but did not complete it, as well as extreme outliers, a sample of 4936 adolescents $(27 \%)$ were included in the analyses (boys $=2264$; girls $=2623$; mean age $=13.6$ years). During data collection, students were free to end the survey at any time and were not required to answer every question in order to participate. Therefore, sample sizes varied for some of the analyses described in the 'Data analysis' section.

\section{Instruments}

\section{Presence of vending machines and logos}

The presence of snack- and beverage-vending machines in the school was assessed by the following questions: 'Does your school have vending machines for chips, candy, or chocolate?' and 'Does your school have vending machines for soft drinks?', respectively. The presence of snack and beverage logos in the school was assessed by 
the following questions: 'Are chip, candy, or chocolate bar company logos visible in your school?' and 'Are soft-drink company logos visible in your school?', respectively. Response options for all questions were 'yes', 'no' or 'don't know'.

\section{Weight status}

Students self-reported their height and weight in the survey, from which BMI was calculated $\left(\mathrm{kg} / \mathrm{m}^{2}\right)$. Students were then categorized as non-overweight, overweight or obese on the basis of International Obesity Task Force cut-off points ${ }^{(23)}$. BMI has been found to be a valid tool for the estimation of overweight and obesity among adolescents in epidemiological studies ${ }^{(24)}$. Validation of the self-reported methods used in Web-SPAN found that measured height and weight were very similar to selfreported values (intraclass correlation coefficient of $0 \cdot 88$ for height and 0.93 for weight) ${ }^{(25)}$.

\section{Dietary intake and diet quality}

A validated ${ }^{(22,26,27)} 24$ h dietary recall was administered to students to measure weekday dietary intake. Students reported all foods and beverages consumed during the previous day. Portion size images and cues regarding beverage intake were provided to help students recall their intake. Diet quality was defined using the number of minimum food group recommendations that were met based on Canada's Food Guide to Healthy Eating ${ }^{(22,28)}$. Individuals were classified as having poor (met $0-1$ food group recommendation), average (met 2-3 food group recommendations) or superior (met all four food group recommendations) diet quality.

\section{Meal behaviours \\ Meal behaviours were measured with twelve items involving frequency of meal consumption and frequency of consuming meals away from home. These questions are similar to the ones developed for Project EAT (Eating Among Teens), a well-established survey instrument ${ }^{(29,30)}$. The frequency of consuming meals from vending machines was assessed by asking 'How often do you eat meals or snacks prepared away from home?' for various locations including vending machines, with response options of 'rarely or never', 'once a month', 'once a week', '2-6 times/week' and 'once a day'. Each response was assigned a score between 1 and 5 ('rarely or never' $=1$, 'once a day' $=5$ ), with higher scores representing a greater frequency of consuming meals away from home. Response options were grouped into three categories: $<2$ times/ month; 1-6 times/week; and at least once a day.}

\section{FFQ}

The FFQ in the present study was taken from the Food Behaviour Questionnaire, which has been validated with students of grades $6-8^{(31)}$. The frequency of salty snack, candy, chocolate bar and pop (a commonly used
Canadian term for soft drinks) consumption was assessed by the question 'How often do you eat or drink these foods?', followed by the response options 'rarely or never', '2-4 times/month', '2-4 times/week', '5-6 times/ week', 'once a day' or 'at least 2 times/day' for each of the food and beverage options. Each response was assigned a score between 1 and 6 ('at least 2 times/day' = 1, 'rarely or never' $=6$ ). Response options were grouped into the following categories: rarely or never; 2 times/month to 4 times/week; at least 5 times/week.

\section{Procedure}

The present research was approved by a university ethics board and by all participating school boards and schools. School boards and schools were contacted by mail and follow-up telephone calls were made to request permission to survey students. Parents and students received information letters, and active parental consent was obtained. All students provided consent after signing on to the web-based survey. The anonymous twenty-fourpage survey took approximately $45 \mathrm{~min}$ to complete and was conducted during class time, on school computers, within the school day. Survey data were collected between January and November 2005 (except in July and August when schools were closed for the summer).

\section{Data analysis}

The reported presence of snack- and beverage-vending machines was assessed with descriptive statistics, as was the reported presence of snack and beverage logos in schools.

To address our first hypothesis, a series of multinomial logistic or ordinal regressions were constructed with generalized estimating equations (GEE) to determine whether the presence of vending machines or logos (snack and/or beverage) in schools was associated with increased probability of students being overweight. The GEE is an extension of the generalized linear models and is useful for analysing data when observations are correlated, such as in schools.

To address the second set of hypotheses, a series of multinomial logistic or ordinal regressions with GEE were constructed to first examine associations between the presence of vending machines and/or logos (snack and/or beverage) and poorer dietary behaviours (frequency of consuming vended goods; frequency of consumption of salty snacks, candy and pop) and diet quality. Next, we tested for associations between students' weight and dietary behaviours (frequency of consuming vended goods; frequency of consumption of salty snacks, candy and pop) and diet quality. Finally, we tested for associations between students' weight and presence of vending machines and/or logos (snack and/or beverage) to determine whether dietary behaviours and/or diet quality attenuated any associations between school environment factors and students' weight. 
Table 1 Associations between school environment factors and body weight status of high-school students in Alberta and the frequency of food and/or beverage purchases from vending machines

\begin{tabular}{|c|c|c|c|c|c|c|}
\hline & \multicolumn{3}{|c|}{ Overweight/obese } & \multicolumn{3}{|c|}{ Frequency of food and/or beverage purchases } \\
\hline & OR & $95 \% \mathrm{Cl}$ & $P$ & OR & $95 \% \mathrm{Cl}$ & $P$ \\
\hline School has snack-vending machines & $0 \cdot 88$ & $0.75,1.04$ & $0 \cdot 144$ & $2 \cdot 41$ & $2 \cdot 10,2 \cdot 78$ & $<0.0001$ \\
\hline School has beverage-vending machines & $1 \cdot 27$ & $1 \cdot 05,1.54$ & 0.015 & $1 \cdot 02$ & $0.90,1.15$ & 0.783 \\
\hline School has beverage logos & $1 \cdot 02$ & $0 \cdot 84,1 \cdot 24$ & $0 \cdot 812$ & $1 \cdot 21$ & $1 \cdot 06,1 \cdot 37$ & 0.004 \\
\hline School has snack logos & 0.91 & $0 \cdot 76,1 \cdot 08$ & 0.274 & 1.61 & $1 \cdot 40,1 \cdot 85$ & $<0.0001$ \\
\hline
\end{tabular}

All analyses control for sex, age, area-level education and area-level income.

Table 2 Associations between school environment factors and frequency of salty snacks, candy and soft drinks consumed

\begin{tabular}{llcrr}
\hline & Category of food & OR & $95 \% \mathrm{Cl}$ & $P$ \\
\hline School has snack-vending machines & Salty snacks & 1.17 & $1.03,1.33$ & 0.01 \\
& Candy & 1.08 & $0.95,1.22$ & 0.23 \\
School has beverage-vending machines & Pop & 0.96 & $0.84,1.10$ & 0.54 \\
School has beverage logos & Pop & 1.15 & $0.99,1.32$ & 0.06 \\
School has snack logos & Salty snacks & 1.34 & $1.18,1.53$ & $<0.0001$ \\
& Candy & 1.34 & $1.18,1.52$ & $<0.0001$
\end{tabular}

All analyses control for sex, age, area-level education and area-level income. Pop is a term commonly used in Canada to refer to soft drinks or 'soda'.

${ }^{*}$ As measured on the FFQ.

Statistical analyses were performed using the Statistical Package for the Social Sciences statistical software package version $15 \cdot 0$ (SPSS Inc., Chicago, IL, USA). All analyses controlled for age, sex and area-level education and income. An $\alpha$-level criterion of $P<0.05$ was used for all statistical comparisons.

\section{Results}

About half (51\%) of the students reported the presence of snack-vending machines in their schools and 62\% reported the presence of beverage-vending machines. Approximately $40 \%$ of students reported the presence of snack logos in their schools and slightly over half (57\%) reported the presence of beverage logos.

The cumulative logit of a child being overweight or obese was $1.27(95 \%$ CI $1.05,1.54, P=0.015)$ for students who reported the presence of beverage-vending machines in their schools compared with those who reported none (Table 1). On the basis of a series of follow-up logistic regressions, this association was not explained by the frequency of pop consumption, frequency of consumption of vended goods or sugar consumption. Furthermore, weight status was not associated with the presence of snack-vending machines or of either type of logo in the school, nor was it associated with the frequency of consuming food from vending machines (OR $=0 \cdot 99$, 95\% CI 0.86, $1 \cdot 15 ; P=895)$.

Students who reported snack-vending machines in their schools were significantly more likely to consume food from vending machines more frequently than those who reported none (see Table 1). Similarly, students who reported the presence of snack or beverage logos in their schools were significantly more likely to consume food from vending machines more frequently than those who reported none. Students who reported the presence of snack-vending machines were significantly more likely to consume salty snacks more frequently than those who reported no snack-vending machines. All other comparisons between the frequency of salty snacks, candy or pop consumption and the reported presence of either type of vending machine in schools were non-significant (see Table 2). Students who reported having snack logos in their schools were significantly more likely to consume candy and salty snacks more frequently than those who reported no snack logos. The reported presence of beverage logos was not associated with students' frequency of pop consumption.

\section{Discussion}

The present study examined associations between various aspects of school food environments (specifically the availability of snack- and beverage-vending machines and the presence of snack and beverage logos) and students' weight, and tested several indices of diet and food behaviours as possible explanatory factors. Roughly half (51\%) of the students reported the presence of snackvending machines and $62 \%$ reported the presence of beverage-vending machines in their schools. This is consistent with other findings indicating a high prevalence of vending machines in schools, particularly in 
middle and high schools ${ }^{(32)}$. For example, in Ontario, Canada's most populous province, $94 \%$ of secondary schools and $32 \%$ of elementary schools have vending machines ${ }^{(5)}$. The presence of beverage logos was more commonly reported (57\%) than the presence of snack $\operatorname{logos}(40 \%)$ in the present study.

The presence of beverage-vending machines in schools was significantly associated with students' overweight and obesity, whereas the presence of snack-vending machines showed no association with students' weight status. Interestingly, neither frequency of vending machine purchases nor pop consumption significantly attenuated the association between beverage-vending machines and weight status.

We found that students' frequency of consuming snacks from vending machines was related to the reported presence of vending machines in schools but not to students' weight status. These two findings are interesting when juxtaposed because it has been hypothesized that the mechanism by which the presence of vending machines in schools influences weight status is through increased use of vending machines and subsequent consumption of vended goods, including sweetened beverages ${ }^{(33,34)}$. However, the reported presence of vending machines was not related to the frequency of pop consumption in our study. Perhaps the presence of vending machines in schools reflects a greater culture of acceptance in terms of students consuming snacks or sweetened beverages typically available in vending machines and encourages students to bring more snacks and sweetened beverages from home. In addition, this finding may reflect the ubiquity of junk food in students' lives, regardless of where they are obtaining it from. Indeed, it has been suggested that students may compensate for the lack of pop at schools by the consumption of other sweetened foods, drinking more outside school or by bringing pop from home ${ }^{(35)}$. Although the presence of vending machines may be associated with increased consumption of vended products, one limitation of the present study, because of its cross-sectional nature, is the inability to draw any conclusions about the hypothesized pathway between the presence of vending machines and weight status over time.

The presence of snack and beverage logos in schools was positively associated with both the frequency of eating from vending machines and the frequency of salty snack and candy consumption in the present study. These results support Breifel et al.'s ${ }^{(33)}$ finding that pouring rights contracts in middle schools were associated with increased consumption of sweetened beverages among students. The fact that logos but not vending machines were associated with the frequency of pop, salty snack and candy consumption may reflect the pervasive nature of pouring rights contracts and the persuasive nature of brand marketing. Specifically, in schools with pouring rights contracts, company food and beverage logos may appear separately from food and beverage products (e.g. logos on clocks, scoreboards), and brand-name products may be made available from sources other than vending machines (e.g. canteens, cafeterias).

There are two main limitations to the present study. First, the study is cross-sectional in nature; thus, only associations can be described, not causation. Future research should use longitudinal designs to determine the effects of pouring rights contracts and the availability of vending machines on students' diet and weight outcomes. Second, because the present study used a self-report measure of the presence of vending machines and food or beverage logos (i.e. students' perceptions of the availability of vending machines and logos were recorded; these perceptions were not confirmed with school staff or site visits), it is possible that the students who did not consume food from vending machines were not as aware that the machines were available as their counterparts who did consume food from vending machines. In other words, a student's awareness of the availability of vending machines may be a proxy measure for the student's use of it.

A major strength of the present study is data collected from a web-based tool that is easy and inexpensive to implement. Researchers have called for valid and reliable tools to assess the larger school environment ${ }^{(36)}$, and a web-based tool may be of value. Future iterations of similar research could incorporate an objective assessment of the school food environment, perhaps completed by administrators or teachers, to assess accessibility of vending machines, food advertising and exclusive contracts within the school food environment.

Our study has implications for practice and policy in school settings. For example, schools have a responsibility to promote health among their students, and school food policies aiming to reduce the availability of high-fat and high-sugar foods are associated with reduced buying of these items ${ }^{(37)}$. Indeed, since conducting the present research, the province of Alberta developed the Alberta Nutrition Guidelines for Children and Youth ${ }^{(38)}$ to provide guidance to schools, daycares and recreational facilities on serving healthier food products. To date, however, these remain voluntary guidelines. The neighbouring Canadian province of British Columbia has implemented the Guidelines for Food and Beverage Sales in $B C$ Schools ${ }^{(39)}$, which provide a mandated policy context for providing healthy food and beverage choices in schools. However, schools benefit financially from the milieu that may contribute to obesity, such as the sponsorship agreements with soft-drink companies ${ }^{(40)}$. Therefore, there are potentially serious budget ramifications of policy initiatives to promote healthy eating. Perhaps as an intermediary measure, the Centers for Disease Control and Prevention recommend that schools should prohibit the sale and distribution of foods of minimal nutritional value (including many snacks and 
sugar-sweetened beverages) until after the end of the last lunch period ${ }^{(41)}$. On an encouraging note, many schools are finding creative means of fund-raising that do not contravene the intent of nutritional guidelines, and the majority of British Columbia schools report a revenueneutral impact of guideline implementation, with a few schools even reporting an increase in revenue ${ }^{(42)}$.

Significant evidence-informed policy advocacy work needs to be carried out in partnership with schools to ensure that school food policies are developed to serve both students' health needs and schools' fiscal realities. Policy examples from Europe may illuminate options for the development of school food policy. For example, the School Food Trust in the $\mathrm{UK}^{(43)}$ has developed national nutritional standards for foods served at schools and aims to improve the quality of school food by providing targeted food- and nutrient-based standards for school food. Similarly, Schools for Health in Europe ${ }^{(44)}$, a partnership between its forty-three member states, the Council of Europe, the European Commission and the WHO Regional Office for Europe, supports a Food and Nutrition Policy for Schools developed by the WHO Regional Office for Europe. Given the fact that the School Food Trust website states that its aims are 'being recognized as increasingly important', it would seem that school food policy development may be only beginning, with public support and recognition of the importance of such policies steadily increasing.

The present study found that the reported presence of snack- and beverage-vending machines and logos in schools is related to some indices of weight status, diet and meal behaviours but not to others. The general hypothesis that the presence of vending machines in schools may affect students' weight through increased consumption of vended goods was supported, but the frequency of junk food consumption does not seem to be related to the presence of vending machines, perhaps reflecting the ubiquity of junk food in the daily lives of students.

\section{Acknowledgements}

The present research was supported by the Alberta Heritage Foundation for Medical Research (AHFMR) and by the Canadian Institutes of Health Research/Heart and Stroke Foundation (CIHR/HSF). L.M.M. received funding from the CIHR and AHFMR (Doctoral Student Awards). K.E.S. received funding from the Danone Institute of Canada (Doctoral Student Award), as well as CIHR/HSF and AHFMR Health Research Studentships. R.C.P. and K.D.R. acknowledge Salary Awards from AHFMR and CIHR. The authors declare that they have no competing interests. L.M.M. performed statistical analyses and wrote the manuscript; K.E.S. contributed to the design of the study and the development of Web-SPAN; coordinated the study including recruitment, data collection and data analysis; and contributed to the preparation of the manuscript; J.C.S. performed the statistical analysis; J.C.S., R.C.P., K.D.R. and L.J.M. contributed to the design of the study and the development of Web-SPAN and contributed to the manuscript; L.J.M. supervised the entire study; L.E.F. provided assistance in recruitment and data collection. All authors edited and approved the final manuscript.

\section{References}

1. Branca F, Nikogosian H \& Lobstein T (2007) The Challenge of Obesity in the WHO European Regions and the Strategies for Response. Copenhagen: WHO Regional Office for Europe.

2. Carter MA \& Swinburn B (2004) Measuring the 'obesogenic' food environment in New Zealand primary schools. Health Promot Int 19, 15-20.

3. Centers for Disease Control and Prevention (1997) Guidelines for school health programs to promote lifelong healthy eating. J Sch Health 67, 9-26.

4. Story M, Kaphingst KM \& French S (2006) The role of schools in obesity prevention. Future Child 16, 109-142.

5. Kroeker C, Manske S, Beyers J et al. (2008) Results from Provincial Implementation of the 2007-2008 School Health Environment Survey. Waterloo, ON: University of Waterloo, PHRED/REDSP, CBRPE.

6. Manitoba Council on Childhood Nutrition (2001) Food and nutrition in Manitoba schools: survey report. http:// www.mast.mb.ca/communications/poverty/MCCN.pdf (accessed August 2009).

7. Berenbaum S (2004) Nutrition in Saskatchewan schools: policy, programs, needs. Heart and Stroke Foundation of Saskatchewan. http://ww1.heartandstroke.sk.ca/images/ English/SK-Nutrition-Report-April-2004.pdf (accessed August 2009).

8. US Government Accountability Office (2005) School meal programs: competitive foods are widely available and generate substantial revenues for schools. Report to Congressional Requesters: GAO-05-563. http://www.gao.gov/ new.items/d05563.pdf (accessed June 2008).

9. Nestle M (2000) Soft drink pouring rights. Public Health Rep 115, 308-319.

10. Opalinski A (2006) Pouring rights contracts and childhood overweight: a critical theory perspective. J Spec Pediatr Nurs 11, 234-243.

11. Swinburn B, Sacks G, Lobstein T et al. (2008) The 'Sydney Principles' for reducing the commercial promotion of foods and beverages to children. Public Health Nutr 11, 881-886.

12. Janssen I, Katzmarzyk PT, Boyce WF et al. (2005) Comparison of overweight and obesity prevalence in school-aged youth from 34 countries and their relationships with physical activity and dietary patterns. Obes Rev 6, 123-132.

13. Jaime P \& Lock K (2009) Do school based food and nutrition policies improve diet and reduce obesity? Prev Med 48, 45-53.

14. Anderson PM \& Butcher KF (2006) Reading, writing, and refreshments - are school finances contributing to children's obesity? J Hum Resour 41, 467-494.

15. Fox MK, Dodd AH, Wilson A et al. (2009) Association between school food environment and practices and body mass index of US public school children. J Am Diet Assoc 109, Suppl. 2, S108-S117.

16. Kubik MY, Lytle LA, Hannan PJ et al. (2003) The association of the school food environment with dietary behaviors of young adolescents. Am J Public Health 93, 1168-1173.

17. Terry-McElrath Y, O'Malley P, Delva J et al. (2009) The school food environment and student body mass index and 
food consumption: 2004 to 2007 National Data. J Adolesc Health 45, Suppl. 3, S45-S56.

18. Briefel R, Crepinsek M, Cabili C et al. (2009) School food environments and practices affect dietary behaviors of US public school children. J Am Diet Assoc 109, Suppl. 2, S91-S107.

19. Fernandes M (2008) The effect of soft drink availability in elementary schools on consumption. J Am Diet Assoc 108, $1445-1452$.

20. Winson A (2008) School food environments and the obesity issue: content, structural determinants, and agency in Canadian high schools. Agric Human Values 25, 499-511.

21. Center for Science in the Public Interest (2007) Are schools making the grade? School nutrition policies across Canada. http://www.cspinet.org/canada (accessed August 2009).

22. Storey KE, Forbes LE, Fraser SN et al. (2009) Diet quality, nutrition and physical activity among adolescents: the WebSPAN (Web-Survey of Physical Activity and Nutrition) project. Public Health Nutr 12, 2009-2017.

23. Cole TJ, Bellizzi MC, Flegal KM et al. (2000) Establishing a standard definition for child overweight and obesity worldwide: international survey. BMJ 320, 1240-1243.

24. Fonseca H, Silva A, Matos M et al. (2010) Validity of BMI based on self-reported weight and height in adolescents. Acta Paediatr 99, 83-88.

25. Calengor K (2007) Nutrition, Physical Activity and Related Health Behaviours in Youth as Assessed by a Web-survey. Edmonton, AB: University of Alberta.

26. Hanning RM, Woodruff SJ, Lambraki I et al. (2007) Nutrient intakes and food consumption patterns among Ontario students in grades six seven and eight. Can J Public Health 98, $12-16$.

27. Hanning RM, Lambraki I, MacDonald C et al. (2004) A WebBased Approach to Nutritional Assessment in Schools. Chicago, IL: International Congress of Dietetics.

28. Health Canada (1992) Canada's Food Guide to Healthy Eating. Ottawa, ON: Health Canada.

29. Neumark-Sztainer D, Story M, Hannan PJ et al. (2002) Weight-related concerns and behaviors among overweight and nonoverweight adolescents - implications for preventing weight-related disorders. Arch Pediatr Adolesc Med 156, 171-178.

30. Neumark-Sztainer D, Wall MM, Story M et al. (2003) Correlates of unhealthy weight-control behaviors among adolescents: implications for prevention programs. Health Psychol 22, 88-98.

31. Hanning RM, Royall D, Toews JE et al. (2009) Web-based food behaviour questionnaire: validation with grades six to eight students. Can J Diet Pract Res 70, 172-178.
32. Kann L, Grunbaum J, McKenna ML et al. (2005) Competitive foods and beverages available for purchase in secondary schools - selected sites, United States, 2004. J Sch Health 75, 370-374.

33. Briefel RR, Wilson A \& Gleason PM (2009) Consumption of low-nutrient, energy-dense foods and beverages at school, home, and other locations among school lunch participants and nonparticipants. J Am Diet Assoc 109, S79-S90.

34. Wiecha JL, Finkelstein D, Troped PJ et al. (2006) School vending machine use and fast-food restaurant use are associated with sugar-sweetened beverage intake in youth. J Am Diet Assoc 106, 1624-1630.

35. Finkelstein E, French S, Variyam JN et al. (editors) (2004) Pros and cons of proposed interventions to promote healthy eating. Am J Prev Med 27, 163-171.

36. Lytle LA \& Fulkerson JA (editors) (2002) Assessing the dietary environment: examples from school-based nutrition interventions. Public Health Nutr 5, 893-899.

37. Neumark-Sztainer D, French SA, Hannan PJ et al. (2005) School lunch and snacking patterns among high school students: associations with school food environment and policies. Int J Behav Nutr Phys Act 2, 14-20.

38. Alberta Health and Wellness (2008) Alberta nutrition guidelines for children youth: a childcare, school and recreation/community centre resource manual. http:// www.healthyalberta.com/Documents/AB_Nutri_Guidelines_ 2008(1).pdf (accessed February 2011).

39. BC Ministry of Education \& Ministry of Healthy Living and Sport (2010) Guidelines for food and beverage sales in BC schools. http://www.bced.gov.bc.ca/health/healthy_ eating/food_guidelines/ (accessed December 2010).

40. Harper MG (2006) Childhood obesity - strategies for prevention. Fam Community Health 29, 288-298.

41. Centers for Disease Control and Prevention (2003) Ten strategies for promoting physical activity, healthy eating, and a tobacco-free lifestyle through school health programs. http://www.cdc.gov/HealthyYouth/publications/ pdf/ten.strategies.pdf (accessed June 2008).

42. BC Ministry of Education \& Ministry of Health (2008) School Food Sales and Policies Provincial Report II. http://www.bced.gov.bc.ca/health/sales_policy_feb08.pdf (accessed December 2010).

43. School Food Trust (2009) School Food Trust: The Standards. http://www.schoolfoodtrust.org.uk/the-standards (accessed February 2011).

44. Schools for Health in Europe (2011) Schools for health in Europe: acting for better schools, leading to better lives. http://www.schoolsforhealth.eu/ (accessed February 2011). 